\title{
Introduction
}

\section{Doing Rural Cultural Studies}

\author{
Clifton Evers, AndRew Gorman-Murray \\ AND EMILY POTTER
}

In 2008, a themed section of Australian Humanities Review began the task of establishing the emerging field of 'Rural Cultural Studies'. As the editors pointed out, 'contemporary cultural studies researchers internationally and in Australia have been massively biased towards urban popular cultures'.1

In the process, metropolitan biases tend to underpin research on cultural change in rural areas-biases which inadequately reflect and respond to the diversity of rural places and communities in Australia, and which often assume that 'contemporary rural cultures are characterised primarily by limitation or lack'.2 Taking up this baton, in 2008 a group of early career researchers (ECRs) participated in two workshops, supported by the Australian Research Council Cultural Research Network, to give further voice to and advance the field of rural cultural studies. Open discussion among these interdisciplinary researchers focused on different aspects of rural cultural research, particularly the diverse scope of 'rural' communities in Australia and their differentiated needs and concerns; the discursive and material relationship between the rural and the urban, and how this is sustained and reworked by governmental policies, cultural activities and media discourses; the under-acknowledged range of everyday cultural practices in rural 
Australia; and notably, the themes of ethical engagement, power and the mediation of meanings and interests in the practice of research-in other words, the 'doing' of rural cultural research with and within regional communities.

The present collection of articles elicits deeper discussions of these themes through specific case studies, as well as theoretical examinations of the nature of their interconnections. The authors combine this discussion with their experiences in the imaginary and material choreography-human and non-human-of social, cultural, political and environmental issues across rural and regional Australia.

These experiences are diverse, pointing to the complexity in the idea of 'rural Australia' which needs some explanation. As David Carter, Kate Darian-Smith and Andrew Gorman-Murray pointed out in their 2008 editorial on rural cultural studies:

In the Australian case, a cluster of overlapping terms-rural, remote, regional, country, pastoral, bush, outback-has emerged in both official and vernacular languages to account for the diversity of 'non-urban' experiences, economic, political and cultural. ${ }^{3}$

This diversity includes a broad range of places, landscapes, people, practices and relationships between these. Rural cultural studies, in drawing on a range of perspectives from cultural studies, history and geography, seeks to elucidate this diversity. 'Rural' places and landscapes, for instance, include coastal and inland areas; farming and fishing villages, mining settlements, Indigenous communities, service towns and larger regional centres; and range across rainforest, (sub-)alpine and (semi-)arid biomes. ' 'Rural' economies, cultures and communities may be based on agrarian, pastoral, mining, Indigenous, tourist or conservation land-uses, and combinations of these. 5 'Rural' populations are as diverse as (and maybe more than) metropolitan ones, including settler, Indigenous and immigrant groups. ${ }^{6}$ 'Rural' practices encompass migration and demographic change; farming systems and counter-cultural communities; human-environment relationships, particularly in a context of environmental fragility and climatic change; Indigenous ownership and settler-Indigenous relations; cultural industries around festivals, tourism, arts and heritage; and media provision, with concerns about broadband and digital modes. ${ }^{7}$ These inventories are still not exhaustive and, moreover, this range of places, landscapes, people and practices interacts in multifarious ways with metropolitan 
centres, populations and imaginaries. ${ }^{8}$ The diversity of rural cultural research is captured in this present collection, which reaches across interior and coastal environments, climatic concerns, Indigenous and settler narratives, infrastructure conflicts, emotional attachments and social power relations both within rural communities and between rural and urban interests. In this way the authors push forward rural cultural studies in new, multi-layered directions.

Questions about the actual 'doing' of rural cultural research deepen this complexity further still. During the processes of conducting research, the authors included in this collection have become progressively more entangled and immersed in the issues and choreographies of the rural and regional fields (in terms of both places and themes) they are investigating. This takes a toll on their bodies and senses of self as they have:

difficulty in clearly distinguishing materials that come from outside (the subject, the field) and from inside (his or her own emotional reactions). The researcher has to struggle with these emotional reactions and anxieties. ... The researcher is, in one way or another, the subject and object of the knowledge that he/she elaborates. ${ }^{9}$

As indicated by the above, researchers must negotiate the behaviour of the subject and place where the research is taking place; the 'disturbances' produced by the activities of the researcher; the emotional, affective and behavioural vagaries of the researcher that influence the research strategies and decisions made or not made; and also their attribution of meaning to observations. ${ }^{10}$

This experience of the in-between presents us with a difficult question: 'Who do you serve?' It's a question that, as Lisa Slater astutely observes, haunts all contributors to this collection. No one has a definitive answer. The people, the institutions, the intellectual project, the human and non-human histories, imaginaries, geographies and architecture all challenge for dominance. Often interests are at odds. Alliances are made, broken, and remade. This means contested concepts and themes emerge from the research that further scramble assumptions and understandings of rural and regional Australia. The articles in this collection reflect, and reflect upon, these contestations around the multifaceted themes, allegiances and spaces of rural cultural research in Australia. To give some order and flow to collection, the articles are arranged under four themes which were 
prominent in our discussions at the two workshops. These themes extend the emerging concerns of rural cultural studies, focusing on issues of place and belonging, human-environment affects and connections, and community dynamics, particularly in relation to the flows and counter-flows of ideas, people and infrastructure between the country and the city.

First, the concepts of place, belonging and the local fuelled much discussion in the workshops. In this collection Emily Potter, Michelle Duffy and Rob Garbutt explore these concepts in detail. Emily Potter thinks through how a poetics of place can produce an ethics of engagement. She explores sociocultural and environmental narratives of the Mallee Country and the high country of the Murray Darling Basin to show us how a rational logic cannot alone sustain a place. Michelle Duffy shakes up the privileging of discursive approaches to understanding these concepts. Michelle does this by taking us into the practices of sound and listening and how they produce deep personal experiences of place, belonging and the local. Rob Garbutt provides a personal self-reflexive account of these concepts through a study of how settlers cleared land on the New South Wales North Coast, where he lives, to install themselves as locals. Rob demonstrates how this act of 'clearing' works to conceal that which came before. However, at the same time the clearing casts light onto the colonising mythologies and narratives that have enabled settlers to produce what Rob calls a 'settler indigeneity'.

Second, weather, climate and landscape were also urgent themes in the workshops. The emotional dimension of these themes comes to the fore in Andrew Gorman-Murray's case study of climate change in Tasmania. Cultural meanings and values are entwined with local landscapes and seasonal patterns. Andrew's research shows that diminishing snow conditions invoke emotional and culturally reflective responses from those that live in localised regions of Tasmania. Emotional attachments to the environment and the (changing) culture-climate nexus hold political potential in that they move people to act to arrest global warming, and to think through the ethical frameworks which tie them to, and impel care for, their local place. Deb Anderson undertakes the difficult task of unpacking how those in rural and regional Australia come to understand, through an interpretive process, the disasters they face as the weather, climate and landscape undergo change. The interpretive process provides a way of coping with, adapting to, and making sense 
of, these disasters. The storytelling mode of these interpretations performs the critical function of enabling an ongoing and open-ended conversation with the weather, climate and landscape. Kim Satchell provides a self-reflexive inquiry into living in a synergistic relationship with a coastal region and its concomitant weather, climate and landscape. Kim's article extends our ethical engagement beyond anthropogenic challenges toward what we share with the more-than-human world and the non-human inhabitants with whose lives we are entangled. The potency of this approach is that an ethical pedagogy of coastal regions can be produced that does not privilege human activity and frameworks.

Third, the entanglement of community and 'conflict' provided considerable challenges at the workshops. Tanya King follows this thread in an article that looks at how political and cultural histories play a crucial role in the successful and ethical implementation of environmental projects in regional Australia. Rather than simply accept at face value that regional Australia is resistant to 'developmental' projects instigated by governments located in major cities, Tanya shows us how it is a lack of procedural justice that concerns the local populations. What is clear is that 'power' is central to research in rural and regional Australia. Rae Dufty works through the relationship she formed with rural public housing communities during her research. Mobilising Michel Foucault's interpretations of power, Rae wrestles with how her research process required her to ethically negotiate the inherent power games that come to underpin the researcher/researched relationship. Rae argues that the dichotomy of 'powerful expert' and 'powerless subject' is a misrepresentation of the dynamic.

Fourth, and extending the focus on rural communities, the immersion of the researcher in rural and regional fieldwork led to a real concern for the wellbeing of the communities with which we work. As such, Lisa Slater takes us into Arukun, Cape York, to explore Indigenous cultural festivals. These festivals, she argues, do not try to impose models of wellbeing but rather actively foster its complex, community-based realisation. Lisa shows us how these festivals function in contrast to government policies that rely on minimising recognition of cultural and historical differences to achieve a sense of wellbeing. Melissa Gregg engages with the specific policy debate of providing broadband in rural Australia. Melissa reveals some of the 
limitations of the complex ideology of fulfilment and wellbeing that dominate the reasoning for provision in this field.

To wrap up the articles, Ross Gibson reflects on the themes and concepts explored within them. Ross argues that the rural cultural studies discussions in this collection rely on an intimacy. This intimacy results in mediation whereby research is done with rather than about rural and regional Australia. The intimacy complicates matters in that the co-presence of the researched and the researcher is beyond mere proximity, located instead in inter- and intra-subjective mediation. This mediation does not simply produce empathy. 'Empathy allows us to talk about what it is to be (like) the other, but it does not raise the question of "what it is to be 'with' the other"'.11 What occurs is that the researcher is marked by the other's knowledge and experience. The ability of the researcher to reduce the meaning of alterity to their own political, moral, and epistemological concerns is scrambled. Anxiety can rise due to an irritating and emotionally risky sense of incomplete control.

What is so fascinating in all these articles is that the authors make use of this anxiety to recognise the experiential asymmetry between the researcher and the researched, and so produce a critical awareness about their location and presence. The anxiety constantly nudges the researchers into critical self-reflection about the cultural and moral assumptions that guide research design, practice and analysis. In this sense, the questions produced by the in-between of the subject and object, researcher and researched, the subjective and the objective, becomes an open-ended choreography, a never-ending practice of the ethics of engagement. That is, the question 'Who do you serve?' does not have an answer, but remains a haunting provocation. Its potency lies in that it performs an attunement of bodies, of subjects and objects towards ethics, at all times.

The articles in this collection show that research is inherently unstable. There are encounters with forms of life, experiences and knowledges that are unexpected, and so transform those involved. This process calls into question our sovereignty by making us infinitely responsible to the Other without having necessarily made a decision to be embroiled in the other's life. ${ }^{12}$ The researcher is held hostage by ethics. This is a research ethics that seeks to maintain tension and discomfort rather than try to level differences. 
What becomes clear in this collection is that while a truly collaborative and wholly ethical project may be a utopian ideal, what is possible is an open-ended, larger and necessary process of mediation-a repositioning, redefining and reworking of power, interests and meaning. This, then, provides a nuanced 'framework' for doing rural cultural research in Australia, one which recognises how the dialogic interchange of 'place' underpins research relationships with diverse rural communities. As such, this collection prompts a rural cultural research agenda built out of, and responsive to, both the complexities of rural lives and our anxieties (as researchers) about our engagements in rural concerns.

\footnotetext{
-NOTES

1 David Carter, Kate Darian-Smith and Andrew Gorman-Murray, 'Rural Cultural Studies: Introduction', Australian Humanities Review, 45, 2008, p. 27.

2 Carter, Darian-Smith and Gorman-Murray, p. 28.

${ }^{3}$ Carter, Darian-Smith and Gorman-Murray, p. 28.

4 Michael Woods, Rural Geography: Processes, Responses and Experiences in Rural Restructuring, Sage, London, 2005; Andrew Gorman-Murray, Kate Darian-Smith and Chris Gibson, 'Scaling the Rural: Reflections on Rural Cultural Studies', Australian Humanities Review, 45, 2008, pp. 37-52.

5 John Holmes, 'Impulses towards a Multifunctional Transition in Rural Australia: Gaps in the Research Agenda', Journal of Rural Studies, vol. 22, no. 1, 2006, pp. 142-160; Gorman-Murray et al, pp. 37-52.

${ }^{6}$ Bruce Missingham, Jacqui Dibden and Chris Cocklin, 'A Multicultural Countryside? Ethnic Minorities in Rural Australia', Rural Society, vol. 16, no. 1, 2006, pp. 131-149; Carter, Darian-Smith and GormanMurray, p. 30.

${ }^{7}$ Carter, Darian-Smith and Gorman-Murray, pp. 27-36.

8 Gorman-Murray, Darian-Smith and Gibson, pp. 37-52.

${ }^{9}$ Alain Giami, 'Counter-Transference in Social Research: Beyond George Devereux', Papers in Social Research Methods-Qualitative Series, no. 7, 2001, <http://www.ethnopsychiatrie.net/giami.htm>. 10 George Devereux, From Anxiety to Method in the Behavioral Sciences, Mouton \& Co., The Hague, 1967, p. xix.

11 Vinciane Despret. 'The Body We Care for: Figures of Anthropo-zoo-gensis', Body \& Society vol. 10, no. 2-3, 2004, pp. 111-34.

12 Emmanuel Levinas, Totality and Infinity: An Essay on Exteriority, trans. Alphonso Lingis, Duquesne University Press, Pittsburgh, 1969.
} 